\title{
Association between childhood trauma and loss of functionality in adult women with fibromyalgia
}

\author{
Associação entre trauma na infância e perda de funcionalidade em mulheres \\ adultas com fibromialgia
}

Ana Paula Mezacaza Filippon, ${ }^{1}$ Diego Garcia Bassani, ${ }^{2}$ Rogério Wolf de Aguiar, ${ }^{1}$ Lúcia Helena Freitas Ceitlin ${ }^{3}$

\begin{abstract}
Objective: To investigate whether history of childhood trauma is associated with loss of functionality in adult women with fibromyalgia (FM). A secondary objective was to assess the presence of differences between depressed and non-depressed adult women with FM in a regression model for functionality. Methods: A total of 114 adult women with FM according to the American College of Rheumatology diagnostic criteria answered the Childhood Trauma Questionnaire and the Fibromyalgia Impact Questionnaire. All subjects were interviewed by trained psychiatrists and evaluated for depression using the Mini International Neuropsychiatric Interview (MINI) - Brazilian version 5.0.0. Correlation and regression models were used to investigate associations between childhood trauma and loss of functionality among patients with FM. The sample was stratified by presence and absence of clinical depression.

Results: Overall, childhood trauma was associated with of loss of functionality in adult women with FM. When stratified by depression, the regression model significantly increased the association among non-depressed patients, even after adjustment for age and use of psychotropic medications.

Conclusions: Childhood trauma showed a clinically important association with loss of functionality among adult women with FM. The associations were more pronounced among subjects without comorbid depression.
\end{abstract}

Keywords: Fibromyalgia, child abuse, depression, activities of daily living.

\begin{abstract}
Resumo
Objetivo: Investigar se a presença de história de trauma na infância está associada com perda de funcionalidade em mulheres adultas com fibromialgia (FM). Um segundo objetivo foi avaliar a presença de diferenças entre mulheres adultas deprimidas e não deprimidas com FM utilizando um modelo de regressão para funcionalidade.

Métodos: Um total de 114 mulheres adultas com FM de acordo com os critérios diagnósticos do American College of Rheumatology responderam o Childhood Trauma Questionnaire e o Questionário de Impacto da Fibromialgia. Todos os indivíduos foram entrevistados por psiquiatras treinados e avaliados para depressão utilizando o Mini International Neuropsychiatric Interview (MINI) - versão brasileira 5.0.0. Modelos de correlação e regressão foram utilizados para investigar associações entre trauma na infância e perda de funcionalidade em pacientes com FM. A amostra foi estratificada pela presença e ausência de depressão clínica.
\end{abstract}

Resultados: Em geral, o trauma na infância esteve associado com perda de funcionalidade em mulheres adultas com FM. Quando estratificadas por depressão, o modelo de regressão aumentou significativamente a associação em pacientes não deprimidos, mesmo após ajuste para idade e uso de medicação psicotrópica.

Conclusões: Trauma na infância esteve associado de forma clinicamente importante à perda de funcionalidade em mulheres adultas com FM. As associações foram mais pronunciadas nos indivíduos sem depressão comórbida.

Descritores: Fibromialgia, sobreviventes adultos de maus-tratos infantis, depressão, atividades cotidianas.

\footnotetext{
${ }^{1}$ Psychiatrist, Universidade Federal do Rio Grande do Sul (UFRGS), Porto Alegre, RS, Brazil. ${ }^{2}$ Epidemiologist, University of Toronto, Toronto, Canada. ${ }^{3}$ Psychiatrist, Hospital de Clínicas de Porto Alegre, UFRGS.

This article was based on Master's dissertation entitled "A influência do trauma infantil no curso da fibromialgia em mulheres" (Influence of childhood trauma on the course of fibromyalgia in women), presented in 2008 at Universidade Federal do Rio Grande do Sul (UFRGS), Porto Alegre, RS, Brazil.

Financial support: none.

Submitted Feb 25 2012, accepted for publication May 13 2012. No conflicts of interest declared concerning the publication of this article.

Suggested citation: Filippon AP, Bassani DG, Aguiar RW, Ceitlin LH. Association between childhood trauma and loss of functionality in adult women with fibromyalgia. Trends Psychiatry Psychother. 2013;35(1):46-54.
} 


\section{Introduction}

Fibromyalgia (FM) is a syndrome characterized by musculoskeletal chronic pain, commonly associated with psychosocial and distress features. Inflammatory and rheumatic markers are usually absent. ${ }^{1}$ It has been demonstrated that FM patients complain of greater disability when compared to patients with other chronic pain disorders, such as complex regional pain syndromes and chronic low back pain. ${ }^{2}$ Also, their quality of life is negatively affected, as has been observed among patients with rheumatoid arthritis. ${ }^{3}$

The precise etiology of FM is unknown. Sensitization of central pain processing mechanisms, ${ }^{4}$ possibly due to a dysregulation of the central stress response, seems to be a decisive element in the genesis of FM. ${ }^{5}$ Since the last decade, many authors have suggested an association between childhood trauma and FM. ${ }^{6-8}$ The neurobiological effects of early trauma may be mediated by chronic under- or overactivation of stress response systems, which may have deleterious effects on neurophysiological body systems ${ }^{9}$ via dysregulation of the hypothalamic-pituitary-adrenal (HPA) axis. ${ }^{5,7}$ The precise dysfunctions in stress regulation via the HPA axis are not yet clear in FM patients; conversely, what is clear is that the body's stress regulatory systems are compromised, and it is possible that the precise nature and combination of each individual's childhood experience may be contributing to the overall symptomatology of FM. ${ }^{10}$ Both distress and pain have been demonstrated to exist as a continuum in the general population and in the clinic, with $\mathrm{FM}$ at the extreme end of the spectrum. ${ }^{11}$ Therefore, it is supposed that FM and depressive disorders (DD) are distinct entities that share common risk factors ${ }^{12}$ and frequently coexist. ${ }^{13}$ Four studies have been conducted in clinical settings to investigate the association between FM and childhood trauma. Three of them found higher rates of self-reported physical and sexual abuse in patients with FM compared to a group with healthy controls, ${ }^{6}$ rheumatoid arthritis ${ }^{8}$ and an "explained pain" control group. ${ }^{7}$ By contrast, the fourth study failed to find an association between sexual abuse and FM compared to healthy controls. ${ }^{14}$ This last study examined lifelong history of sexual abuse, not childhood abuse.

Furthermore, some studies have examined nontreatment-seeking individuals. Alexander et al., for example, concluded that lifelong sexual and physical abuse are more strongly associated with seeking health care than with FM itself. ${ }^{15}$ Only one study assessing a community sample and investigating sexual and physical abuse failed to find associations between childhood trauma and FM. ${ }^{16}$

Finally, some data suggest a consistent relationship between history of trauma and FM symptom severity. ${ }^{8}$ According to some studies, patients reporting childhood trauma experience greater psychological distress, have more severe physical symptoms, greater functional disability, poorer psychological adjustment, ${ }^{14,17}$ and use more health care services and pain medications. ${ }^{15}$ Also, patients with high tender point counts are more likely to have experienced adverse childhood experiences, such as loss of a parent or abuse. ${ }^{18}$

Few studies have explored the impact of a history of childhood trauma on the functionality of adult patients with FM, and especially the effect of DD on this relationship. Failure to use psychometrically validated dimensional instruments to measure functionality loss has been a particular difficulty in previous studies of FM.

This study aims to investigate whether the presence of history of childhood trauma is associated with loss of functionality in adult women with FM. A second objective was to assess the presence of differences between depressed and non-depressed adult women with FM in a regression model for functionality.

\section{Subjects and Methods}

\section{Sample}

The sample comprised all female patients who sought medical care at the Pain and Palliative Care Department Program at Hospital de Clínicas de Porto Alegre from April 2005 to April 2006, and from June 2007 to November 2007 and fulfilled the American College of Rheumatology diagnostic criteria for FM. ${ }^{1}$ Patients under the age of 18 and those who had significant reading and writing difficulties were excluded. A total of 145 patients were considered eligible; of these, 114 (79\%) completed the interviews and are included in the present analysis. None of the patients who met the inclusion criteria refused to participate in the study. In 31 patients, interviews could not be completed due to locomotor disability or incorrect contact numbers. In order to guarantee confidentiality and anonymity, self-report questionnaires were applied individually and in person in a private room. Demographic data from patients who completed the assessment were compared to those of patients who did not complete the assessment and yielded non-significant differences.

The study was approved by the Research Ethics Committee of Hospital de Clínicas de Porto Alegre (protocol no. 05-330), and all patients signed an informed consent form before entering the study.

\section{Hypothesis}

Our hypothesis was that self-reported childhood trauma would be associated with loss of functionality 
among adult women with FM, even after adjustment for age and use of medication. We also hypothesized that the association would be more pronounced in depressed vs. non-depressed patients.

\section{Assessments}

Demographic and clinical data were collected during individual interviews. All patients were asked about the presence of comorbid pain conditions and use of psychotropic medications, defined as the daily use of therapeutic doses of antidepressants, anticonvulsivants, antipsychotics, benzodiazepines, or lithium, or any doses of tricyclic antidepressants. Use of psychotropic medication was defined as the daily use of any dose of antidepressants or benzodiazepines.

\section{Childhood trauma}

Childhood trauma was measured using the short form of the Childhood Trauma Questionnaire (CTQ). ${ }^{19}$ The CTQ is a 28-item, self-report measure widely used to assess history of childhood abuse and neglect. It assesses the experience of different types of abuse and neglect, with five items measuring each type of trauma on a 5-point scale ranging from never true to very often true. The scale yields a total score and five subscale scores, including the following domains: 1) childhood physical abuse, bodily assaults on a child by an older person that pose a risk of, or result in, injury; 2) childhood emotional abuse, verbal aggression that affects the welfare or morale of the child, or any conduct that humiliates, embarrasses, or threatens the child; 3) childhood sexual abuse, any type of sexual contact or conduct between a child and someone older; 4) childhood emotional neglect, failure of caretakers to provide for basic emotional and psychological needs, such as love, motivation, and support; and 5) childhood physical neglect, failure of caretakers to provide for basic physical needs, such as feeding, home, security, supervision, and health. ${ }^{19,20}$ The scale has demonstrated internal consistency in numerous clinical samples, with reliability coefficients ranging from 0.95 (sexual abuse) to 0.60 (physical neglect). Test-retest reliability after a period ranging from 1.6 to 5.6 months was between 0.79 (physical neglect) and 0.81 (sexual abuse and emotional neglect). ${ }^{21}$ This study used the Portuguese version of the CTQ. ${ }^{22}$ Childhood trauma was categorized according to the cutoff points recommended by Bernstein \& Fink. ${ }^{20}$

\section{Functionality}

The Fibromyalgia Impact Questionnaire (FIQ) was used to score patient functionality. ${ }^{23}$ The FIQ consists of
10 self-report questions. The scores of each item are standardized on a scale ranging from 0 to 10 , with higher scores indicating a higher level of impairment. The FIQ has been validated in Portuguese and has been shown to be a reliable and valid instrument to measure the functionality and health status of FM patients in Brazil. ${ }^{24}$ Based on data obtained by Cacace et al., total score values $\geq 66.85$ were considered to indicate moderate to severe dysfunction. ${ }^{25}$

\section{Depression}

Subjects were evaluated using a clinical interview and the Mini International Neuropsychiatric Interview (MINI) - Brazilian version 5.0.0, a standardized and structured diagnostic interview based on the Diagnostic and Statistical Manual of Mental Disorders, 4th edition (DSM-IV). ${ }^{26}$ The MINI evaluates major axis I psychiatric disorders according to DSM-IV criteria, is widely used in clinical and research evaluations, and was applied in our stud by trained psychiatrists.

\section{Statistical analysis}

CTQ scores were stratified by presence of major depression and loss of functionality. Patients with functionality scores $\geq 66.85$, considered to present a moderate to severe loss of functionality, were compared to patients with scores $<66.85$, considered to present mild functional loss. ${ }^{25}$ The recommended cutoff points were used to define presence or absence of any trauma and also the presence or absence of each different type of trauma measured by the CTQ. ${ }^{20}$ To facilitate analysis, CTQ total scores were also categorized into tertiles; for each tertile, the corresponding functionality rates are reported.

Data were analyzed using the Statistical Package for the Social Sciences (SPSS) version 15.0 for Windows and Stata version 10.0. Quantitative variables were expressed as means and standard deviation, and categorical variables, as relative frequencies (percentages). Quantitative variables obtained in different functionality categories were compared using the Student $t$ test for independent samples; the chi-square test was used for categorical variables. All analyses were two-tailed. Significance was set at 0.05 .

Multiple linear regression analysis was performed to evaluate the relationship between functionality (dependent variable) and different forms of trauma (factors being studied). The sample was stratified by presence or absence of depression. Depression was defined according to DSM-IV criteria for major depressive episode at the time of the interview. The analysis was adjusted for age and use of psychotropic medication. 


\section{Results}

Table 1 shows the characteristics of the sample in terms of sociodemographic variables, comorbid pain conditions, and use of psychotropic medications.

Table 1 - Sociodemographic and clinical characteristics of 114 adult women with fibromyalgia

\begin{tabular}{|c|c|}
\hline Variable & n (\%) \\
\hline Age, mean (SD) & $49.5(11.17)$ \\
\hline \multicolumn{2}{|l|}{ Ethnicity } \\
\hline Caucasian & $95(83.3)$ \\
\hline Non-Caucasian & $19(16.7)$ \\
\hline \multicolumn{2}{|l|}{ Marital status } \\
\hline Single & $23(20.2)$ \\
\hline Married & $62(54.4)$ \\
\hline Separated/divorced & $20(17.5)$ \\
\hline Widowed & $9(7.9)$ \\
\hline \multicolumn{2}{|l|}{ Education } \\
\hline Less than primary & $60(52.6)$ \\
\hline Primary & $20(17.6)$ \\
\hline Secondary & $26(22.8)$ \\
\hline College/university & $8(7.0)$ \\
\hline \multicolumn{2}{|l|}{ Occupation } \\
\hline Student & $2(1.7)$ \\
\hline Employed & $57(50.0)$ \\
\hline Disability insurance & $41(36.0)$ \\
\hline Unemployed & $10(8.8)$ \\
\hline Retired & $4(3.5)$ \\
\hline \multicolumn{2}{|l|}{ Family income } \\
\hline$<1$ minimum wage & $62(54.4)$ \\
\hline 1-2 minimum wages & $32(28.1)$ \\
\hline 2-4 minimum wages & $14(12.3)$ \\
\hline 4-6 minimum wages & $4(3.5)$ \\
\hline$>6$ minimum wages & $1(1.7)$ \\
\hline \multicolumn{2}{|l|}{ Psychotropic medication* } \\
\hline None & $35(30.7)$ \\
\hline Amitriptyline ( $\leq 25 \mathrm{mg}$ daily) & $39(34.2)$ \\
\hline Tricyclics (> 50 mg daily) & $10(8.8)$ \\
\hline SSRIs & $9(7.9)$ \\
\hline Tricyclics and SSRIs & $17(14.9)$ \\
\hline Benzodiazepines & $9(7.9)$ \\
\hline \multicolumn{2}{|l|}{ Comorbid pain diagnosis } \\
\hline No & $66(57.9)$ \\
\hline Yes & $48(42.1)$ \\
\hline
\end{tabular}

The most prevalent forms of self-reported childhood trauma were emotional neglect (75.4\%) and physical neglect $(75.4 \%)$, followed by emotional abuse $(69.3 \%)$, physical abuse (54.4\%), and sexual abuse (35.1\%). One hundred and ten individuals (96.5\%) reported at least one type of childhood trauma. Table 2 shows these numbers stratified by loss of functionality and depression.

The linear regression model (Table 3 ) revealed a significant decrease in functionality in the presence of any level of emotional neglect and moderate to severe levels of emotional abuse, physical abuse, physical neglect, and sexual abuse when compared to those reporting the lowest scores (no trauma). When the sample was stratified according to the presence of depression, patients with depression showed overall higher FIQ scores compared to those without depression. Conversely, the linear association between trauma scores and loss of functionality was more marked in all categories mentioned above among patients without depression when compared to depressed individuals. These associations were less pronounced for sexual abuse, probably due to the relatively low prevalence of self-reports, which had a strong influence on the estimates, especially when the sample was stratified (due to the increased variance in the resulting subsamples).

The regression model using CTQ total scores as the independent variable showed an association between trauma scores and loss of functionality. This association was also more pronounced in the group of patients without depression when compared to the group of depressed patients. Nevertheless, the depressed group showed higher overall scores for loss of functionality when compared to the non-depressed group (Table 3).

Table 2 - СTQ scores stratified by presence of major depression and classified in terms of loss of functionality according to the FIQ in adult women with fibromyalgia

\begin{tabular}{|c|c|c|c|c|c|c|}
\hline & \multicolumn{3}{|c|}{ Depressed, n (\%) } & \multicolumn{3}{|c|}{ Non-depressed, n (\%) } \\
\hline & $\begin{array}{l}\text { Mild loss of } \\
\text { functionality } \\
\text { FIQ }<66.85\end{array}$ & $\begin{array}{c}\text { Moderate/severe } \\
\text { loss of functionality } \\
\text { FIQ } \geq 66.85\end{array}$ & Total & $\begin{array}{l}\text { Mild loss of } \\
\text { functionality } \\
\text { FIQ }<66.85\end{array}$ & $\begin{array}{c}\text { Moderate/severe } \\
\text { loss of functionality } \\
\text { FIQ } \geq 66.85\end{array}$ & Total \\
\hline \multicolumn{7}{|l|}{ Childhood trauma } \\
\hline 1st tertile CTQ & $8(36.4)$ & $8(18.6)$ & $16(24.6)$ & $18(64.3)$ & $3(14.3)$ & $21(42.8)$ \\
\hline 2nd tertile CTQ & $11(50.0)$ & $12(27.9)$ & $23(35.4)$ & $8(28.6)$ & $9(42.9)$ & $17(34.7)$ \\
\hline 3rd tertile CTQ & $3(13.6)$ & $23(53.5)$ & $26(40.0)$ & $2(7.1)$ & $9(42.9)$ & $11(22.5)$ \\
\hline \multicolumn{7}{|l|}{ Any trauma } \\
\hline Yes & $21(95.5)$ & $43(100.0)$ & $64(98.5)$ & $25(89.3)$ & $21(100.0)$ & 46 (93.9) \\
\hline No & $1(4.5)$ & $0(0.0)$ & $1(1.5)$ & $3(10.7)$ & $0(0.0)$ & $3(6.1)$ \\
\hline \multicolumn{7}{|l|}{ Type of trauma } \\
\hline Emotional abuse & $12(54.5)$ & $36(83.7)$ & $48(73.8)$ & $15(53.6)$ & $16(76.2)$ & $31(63.3)$ \\
\hline Physical abuse & $10(45.5)$ & $29(67.4)$ & $39(60.0)$ & $9(32.1)$ & $14(66.7)$ & $23(46.9)$ \\
\hline Sexual abuse & $6(27.3)$ & $20(46.5)$ & $26(40.0)$ & $6(21.4)$ & $8(38.1)$ & $14(28.6)$ \\
\hline Emotional negligence & $16(72.7)$ & $36(83.7)$ & $52(80.0)$ & $14(50.0)$ & $20(95.2)$ & $34(69.4)$ \\
\hline Physical negligence & $18(81.8)$ & $34(79.1)$ & $52(80.0)$ & $15(53.6)$ & $19(90.5)$ & $34(69.4)$ \\
\hline
\end{tabular}

$\mathrm{CTQ}=$ Childhood Trauma Questionnaire; FIQ = Fibromyalgia Impact Questionnaire. 
Table 3 - Linear regression models estimating the association between loss of functionality according to the FIQ and CTQ scores stratified by presence of major depression in adult women with fibromyalgia

\begin{tabular}{|c|c|c|c|c|c|c|c|c|c|}
\hline & \multicolumn{3}{|c|}{ Depressed } & \multicolumn{3}{|c|}{ Non-depressed } & \multicolumn{3}{|c|}{ Total } \\
\hline & Beta & $95 \% \mathrm{CI}$ & $\mathbf{p}$ & Beta & $95 \% \mathrm{CI}$ & $\mathbf{p}$ & Beta & $95 \% \mathrm{CI}$ & $\mathbf{p}$ \\
\hline \multicolumn{10}{|c|}{ Emotional abuse } \\
\hline No & ref & & & ref & & & ref & & \\
\hline Mild & 1.30 & -7.45 to -10.04 & 0.768 & 6.53 & -3.87 to -16.94 & 0.213 & 4.46 & -2.70 to -11.62 & 0.22 \\
\hline Moderate & 7.65 & -2.36 to -17.65 & 0.132 & 20.00 & 5.72 to 34.28 & 0.007 & 14.59 & 5.80 to 23.38 & 0.001 \\
\hline Severe & 17.20 & 8.57 to 25.83 & 0.0001 & 19.57 & 7.20 to 31.93 & 0.003 & 21.05 & 13.50 to 28.59 & 0.0001 \\
\hline \multicolumn{10}{|c|}{ Emotional neglect } \\
\hline No & ref & & & ref & & & ref & & \\
\hline Mild & -4.10 & -13.75 to -5.54 & 0.398 & 19.71 & 10.53 to 28.88 & 0.0001 & 9.03 & 1.47 to 16.59 & 0.02 \\
\hline Moderate & 7.97 & -2.64 to -18.58 & 0.138 & 23.08 & 13.47 to 32.69 & 0.0001 & 16.75 & 8.59 to 24.91 & 0.0001 \\
\hline Severe & 11.71 & 2.44 to 20.98 & 0.014 & 31.45 & 21.57 to 41.34 & 0.0001 & 23.91 & 16.41 to 31.42 & 0.0001 \\
\hline \multicolumn{10}{|l|}{ Physical abuse } \\
\hline No & ref & & & ref & & & ref & & \\
\hline Mild & 1.76 & -10.10 to -13.63 & 0.768 & 4.95 & -7.29 to -17.20 & 0.42 & 2.90 & -6.21 to -12.01 & 0.529 \\
\hline Moderate & 1.44 & -8.29 to -11.16 & 0.769 & 17.53 & 2.73 to 32.32 & 0.021 & 9.64 & 0.95 to 18.32 & 0.03 \\
\hline Severe & 11.81 & 3.52 to 20.10 & 0.006 & 18.84 & 7.56 to 30.11 & 0.002 & 16.96 & 9.83 to 24.08 & 0.0001 \\
\hline \multicolumn{10}{|c|}{ Physical neglect } \\
\hline No & ref & & & ref & & & ref & & \\
\hline Mild & 2.07 & -10.57 to -14.71 & 0.745 & -3.45 & -15.26 to -8.36 & 0.559 & 1.81 & -7.99 to -11.61 & 0.715 \\
\hline Moderate & 2.28 & -8.00 to -12.57 & 0.659 & 21.53 & 12.11 to 30.95 & 0.0001 & 12.91 & 5.03 to 20.80 & 0.002 \\
\hline Severe & 7.88 & -2.32 to -18.08 & 0.127 & 20.60 & 10.61 to 30.59 & 0.0001 & 16.38 & 8.40 to 24.36 & 0.0001 \\
\hline \multicolumn{10}{|l|}{ Sexual abuse } \\
\hline No & ref & & & ref & & & ref & & \\
\hline Mild & 8.97 & -2.79 to -20.73 & 0.132 & 6.92 & -7.39 to -21.23 & 0.335 & 8.19 & -1.59 to -17.98 & 0.1 \\
\hline Moderate & 3.46 & -9.10 to -16.02 & 0.584 & 20.32 & 3.22 to 37.41 & 0.021 & 11.28 & 0.31 to 22.24 & 0.044 \\
\hline Severe & 9.05 & -0.12 to -18.22 & 0.053 & 9.92 & -7.18 to -27.01 & 0.249 & 12.75 & 4.00 to 21.50 & 0.005 \\
\hline \multicolumn{10}{|c|}{ Total trauma (CTQ) } \\
\hline 1 tertile & ref & & & ref & & & ref & & \\
\hline 2 tertile & 1.80 & -6.81 to -10.42 & 0.677 & 19.36 & 11.50 to 27.23 & 0.0001 & 12.30 & 5.92 to 18.67 & 0.0001 \\
\hline 3 tertile & 14.20 & 5.79 to 22.61 & 0.001 & 28.34 & 19.37 to 37.32 & 0.0001 & 24.15 & 17.65 to 30.65 & 0.0001 \\
\hline
\end{tabular}

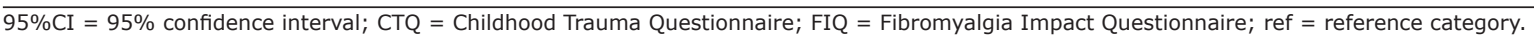

Table 4 - Adjusted linear regression models estimating the association between loss of functionality according to the FIQ and CTQ scores stratified by presence of major depression (adjusted for age and use of psychotropic medication*) in adult women with fibromyalgia

\begin{tabular}{|c|c|c|c|c|c|c|c|c|c|}
\hline & \multicolumn{3}{|c|}{ Depressed } & \multicolumn{3}{|c|}{ Non-depressed } & \multicolumn{3}{|c|}{ Total } \\
\hline & Beta & $95 \% \mathrm{CI}$ & $\mathbf{p}$ & Beta & $95 \% \mathrm{CI}$ & $\mathbf{p}$ & Beta & $95 \% \mathrm{CI}$ & $\mathbf{p}$ \\
\hline \multicolumn{10}{|c|}{ Emotional abuse } \\
\hline No & ref & & & ref & & & ref & & \\
\hline Mild & 1.04 & -7.58 to -9.65 & 0.81 & 8.04 & -2.41 to -18.49 & 0.128 & 5.43 & -1.48 to -12.35 & 0.122 \\
\hline Moderate & 7.58 & -2.58 to -17.74 & 0.141 & 17.85 & 3.59 to 32.11 & 0.015 & 14.74 & 6.19 to 23.29 & 0.001 \\
\hline Severe & 16.54 & 7.96 to 25.11 & 0.0001 & 20.47 & 8.28 to 32.65 & 0.002 & 20.31 & 13.03 to 27.59 & 0.0001 \\
\hline \multicolumn{10}{|c|}{ Emotional neglect } \\
\hline No & ref & & & ref & & & ref & & \\
\hline Mild & -4.89 & -14.46 to -4.68 & 0.311 & 18.89 & 9.56 to 28.22 & 0.0001 & 8.35 & 0.88 to 15.81 & 0.029 \\
\hline Moderate & 8.19 & -2.29 to -18.68 & 0.123 & 21.67 & 11.75 to 31.58 & 0.0001 & 15.89 & 7.84 to 23.93 & 0.0001 \\
\hline Severe & 9.88 & 0.51 to 19.25 & 0.039 & 30.65 & 20.58 to 40.73 & 0.0001 & 21.91 & 14.37 to 29.45 & 0.0001 \\
\hline \multicolumn{10}{|l|}{ Physical abuse } \\
\hline No & ref & & & ref & & & ref & & \\
\hline Mild & 2.36 & -9.35 to -14.07 & 0.688 & 4.41 & -7.71 to -16.53 & 0.4467 & 3.29 & -5.45 to -12.03 & 0.457 \\
\hline Moderate & 1.28 & -8.34 to -10.90 & 0.791 & 17.20 & 2.63 to 31.76 & 0.022 & 9.61 & 1.27 to 17.95 & 0.024 \\
\hline Severe & 11.27 & 3.07 to 19.46 & 0.008 & 19.62 & 8.54 to 30.71 & 0.001 & 16.53 & 9.70 to 23.35 & 0.0001 \\
\hline \multicolumn{10}{|c|}{ Physical neglect } \\
\hline No & ref & & & ref & & & ref & & \\
\hline Mild & 3.79 & -8.71 to -16.29 & 0.546 & -5.60 & -17.97 to -6.77 & 0.366 & 0.00 & -9.50 to -9.50 & 1 \\
\hline Moderate & 2.64 & -7.44 to -12.73 & 0.602 & 20.98 & 10.66 to 31.30 & 0.0001 & 10.87 & 3.15 to 18.59 & 0.006 \\
\hline Severe & 8.49 & -1.65 to -18.63 & 0.099 & 21.75 & 10.94 to 32.56 & 0.0001 & 16.13 & 8.27 to 23.99 & 0.0001 \\
\hline \multicolumn{10}{|l|}{ Sexual abuse } \\
\hline No & ref & & & ref & & & ref & & \\
\hline Mild & 9.53 & -1.97 to -21.03 & 0.103 & 4.44 & -10.17 to -19.06 & 0.543 & 6.99 & -2.55 to -16.53 & 0.149 \\
\hline Moderate & 2.97 & -9.32 to -15.26 & 0.63 & 18.37 & 1.18 to 35.56 & 0.037 & 9.79 & -0.90 to -20.49 & 0.072 \\
\hline Severe & 9.14 & -0.02 to -18.31 & 0.05 & 11.17 & -6.71 to -29.05 & 0.214 & 11.31 & 2.46 to 20.15 & 0.013 \\
\hline \multicolumn{10}{|c|}{ Total trauma (CTQ) } \\
\hline 1 tertile & ref & & & ref & & & ref & & \\
\hline 2 tertile & 1.72 & -6.78 to -10.22 & 0.688 & 17.98 & 9.81 to 26.14 & 0.0001 & 11.23 & 4.95 to 17.50 & 0.0001 \\
\hline 3 tertile & 13.62 & 5.30 to 21.95 & 0.002 & 27.71 & 18.63 to 36.79 & 0.0001 & 22.66 & 16.22 to 29.10 & 0.0001 \\
\hline
\end{tabular}

95\%CI = 95\% confidence interval; CTQ = Childhood Trauma Questionnaire; FIQ = Fibromyalgia Impact Questionnaire; ref = reference category.

* Daily use of any dose of anticonvulsivants, antidepressants, antipsychotics, or benzodiazepines. 
Table 4 shows the results of the linear regression model used to estimate the association between functional loss and trauma scores after adjustment for age and use of psychotropic drugs. Severe forms of emotional neglect were strongly associated with loss of functionality in both depressed (beta $=16.54 ; 95 \%$ confidence interval [95\%CI] 7.96-25.11) and nondepressed groups (beta $=20.47 ; 95 \%$ CI 8.28-32.65) . Severe forms of physical abuse were also strongly associated with loss of functionality in depressed (beta = 11.27; 95\%CI 3.07-19.46) and non-depressed patients (beta $=19.67 ; 95 \%$ CI 8.54-30.71). Moderate forms were associated with decreased functionality only in the non-depressed group, and mild forms of emotional and physical abuse were not associated with the outcome in any of the groups studied.

All intensities of emotional neglect were strongly associated with loss of functionality in the nondepressed group: mild (beta $=18.89$; 95\%CI 9.5628.22 ), moderate (beta $=21.67 ; 95 \%$ CI 11.75-31.58), and severe (beta $=30.65 ; 95 \%$ CI 20.58-40.73). In the depressed group, emotional neglect was associated with loss of functionality only in the most severe subgroup (beta $=9.88 ; 95 \%$ CI $0.51-19.25$ ) and in a less marked way. Physical neglect was not associated with loss of functionality in the depressed group, but was significantly associated with the outcome in moderate to severe forms (beta $=9.88 ; 95 \% \mathrm{CI} 0.51-19.25$ ) in the non-depressed group. Sexual abuse was significantly associated with loss of functionality in moderate forms in the non-depressed group (beta $=18.37 ; 95 \% \mathrm{CI} 1.18$ 35.56) and in the severe subgroup in both depressed and non-depressed patients (beta $=11.31 ; 95 \% \mathrm{CI}$ 2.46-20.15).

\section{Discussion}

Our study indicates that self-reported childhood trauma is strongly associated with loss of functionality among adult women with FM (clinical sample), even after adjustment for age and use of medication. Our findings are in agreement with previous studies involving tertiary care patients that also found an association between FM and childhood trauma. ${ }^{6-8}$ We confirm and extend those previous findings by suggesting that childhood trauma predicts more severe presentations of FM.8,14,17 The stronger association between loss of functionality and different forms of neglect (albeit not statistically significant) when compared with abuse may suggest a most harmful effect of neglect on the presentation of FM.

Compared to the participants included in a recently published paper$^{27}$ greater proportions were observed in all types of trauma, except for emotional abuse in a sample of patients with panic disorders. Also using the CTQ, a Brazilian study found that patients with panic disorders had a $65.5 \%$ prevalence of emotional neglect, $49.4 \%$ of physical neglect, $71.3 \%$ of emotional abuse, $46.0 \%$ of physical abuse, and $19.5 \%$ of sexual abuse, compared with even lower proportions in a non-clinical control group: $39.1 \%$ of emotional neglect, $35.6 \%$ of physical neglect, $48.3 \%$ of emotional abuse, $25.3 \%$ of physical abuse, and $9.2 \%$ of sexual abuse. ${ }^{27}$

Furthermore, our results reveal that such association is even more pronounced in non-depressed patients, when compared to those with depression. It should be noted that this effect was also present in depressed patients, who scored higher for loss of functionality overall when compared to non-depressed patients. These findings have not been previously reported in the literature and are of great interest, therefore deserving careful consideration.

We observed a different degree of association between childhood trauma scores and loss of functionality among individuals with depression vs. those without depression (Figure 1). This finding suggests that, in the presence of childhood trauma, some (non-depressed) individuals may develop different forms of functional loss than others (depressed). Also, among some individuals (mainly non-depressed), a clear gradient (of functional loss) was observed as trauma scores increased, suggesting the expression of trauma consequences in a somatic (physical) mode through loss of functionality. Conversely, other individuals may express the consequences of such events in a more psychological mode, such as depression. We suspect that these latter individuals are the ones classified as depressive in our sample, who showed a less clear gradient of functional loss, but still significant in severe forms of trauma as trauma scores increased. Also, some aspects of quality of life that may be affected by childhood trauma or depression (e.g., sleep quality, cognition, self-esteem, and sexuality) are not covered by the FIQ and consequently were not investigated in the present study. ${ }^{28}$

Childhood trauma is known to be a risk factor for many pathological conditions, such as depression and chronic fatigue syndrome, ${ }^{29}$ and has been associated with suicide attempts, multiple sex partners, sexually transmitted diseases, use of tobacco and alcohol, physical inactivity, severe obesity, ischemic heart disease, cancer, chronic lung disease, skeletal fractures, liver disease, ${ }^{30}$ and post-traumatic stress disorder. ${ }^{31}$ Notwithstanding, childhood trauma does not always lead to impairing conditions - and, even if it did, the conditions would not always be the same. Genetic predisposition may influence the individual's degree of 


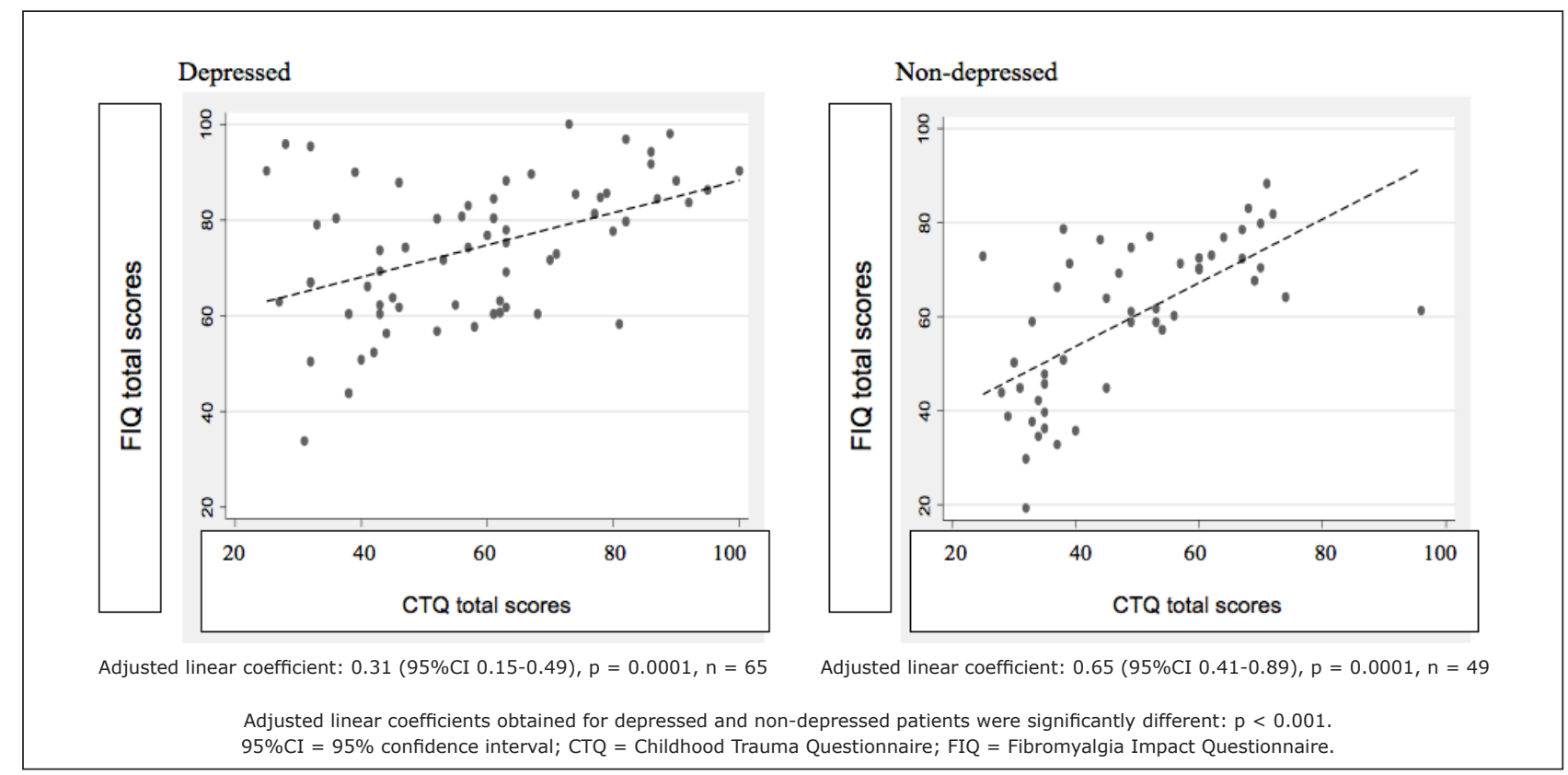

Figure 1 - Association between loss of functionality according to the FIQ and CTQ scores stratified by presence of major depression in adult women with fibromyalgia

susceptibility to the effects of early trauma, possibly based on how the brain responds to stress, and may also determine the pathological entity to which the individual is rendered vulnerable as a consequence of stress. ${ }^{32}$ The type of trauma and the perpetrator are, most likely, also implicated in the consequences, as are the intensity and duration of traumatic events.

There may be important differences in the natural progression of FM and consequences that may have been interpreted by some authors as different entities, sometimes referred to as different FM subtypes. According to some authors, it is possible to distinguish between a subgroup of patients with high pain sensitivity and no associated psychiatric diagnosis (possibly associated with inflammatory rheumatic conditions), a second subgroup with comorbid pain-related depression, a third subgroup characterized by depression with concomitant FM, and a fourth group with somatoform pain disorder of the FM type. ${ }^{33}$ In the second subgroup, depression comes after the onset of FM, whereas in the third subgroup, FM comes after depression. We did not collect the necessary data to distinguish between these possible subtypes of FM. However, it is arguable that our depressed individuals fall under the second (comorbid pain-related depression) and third (depression with concomitant FM) categories, and that most of our non-depressed individuals belong to the group with somatoform pain disorder. This would explain the stronger association between early trauma and loss of functionality among our non-depressed patients.
Insufficient data in the literature reinforce speculation as to why adult women with FM and a history of childhood trauma show different changes in functionality in the presence vs. absence of depression. The results obtained in our sample are counterintuitive. An intuitive hypothesis would be that the presence of depression would increase the loss of functionality as a deleterious effect of trauma. Contradicting this hypothesis are some psychoanalytical theories advocating that the child, due to an immaturity of his/her mental apparatus and a reduced organizational capacity, will have lower chances of adequately responding to excessively exciting situations when compared to an adult. There is a whole range of possible failures in psychic structuring caused by early trauma, experienced perhaps even before the acquisition of language. In such cases, character traits or attachment to narcissistic values serve instead of purely mental defenses. Recourse to a somatic solution is frequent, short-circuiting any psychic workingthrough, such as acting out in borderline patients. This phenomenon has been called by some authors as an acting-in in the body. ${ }^{34}$

Because the association between childhood trauma scores and loss of functionality showed a stronger linear gradient in the group of patients without depression, a possible explanation could be that depression is either a confounding factor or an effect modifier - depression is also associated with history of childhood trauma and may result in loss of functionality as measured by the FIQ. ${ }^{28}$ This hypothesis is supported by the estimates obtained in 
our stratified analysis, which were substantially different between the two subgroups, and justifies our choice for stratification. Further studies (preferably longitudinal ones) are warranted to further investigate the role of depression in the association between childhood trauma and loss of functionality.

This sample showed an extremely high prevalence of childhood trauma: $96.5 \%$ of the patients reported some type of trauma (including those with a mild intensity). This finding may have been influenced by either 1) selection bias, 2) our choice of categorization, or 3) recall bias, as will be discussed below.

1) A convenience sample was used, selected at a high-complexity pain treatment center known to attract patients with a history of childhood trauma, as opposed to patients without such characteristic. ${ }^{15} \mathrm{We}$ also observed that patients with a history of childhood trauma are more likely to seek health treatment in general when compared to the general population. ${ }^{35}$ This behavior has likely contributed to the high prevalence of trauma observed.

2) The cutoff points used for trauma scores were defined by Bernstein \& Fink and only studied in American populations. ${ }^{20}$ We compared the American cutoff points to data from a recently published study that used CTQ in a Brazilian sample. ${ }^{27}$ That case-control study included 123 patients with panic disorder and 123 paired healthy controls which were evaluated for childhood trauma using the CTQ; the aim of the study was to evaluate the association between childhood trauma and quality of parental bonding in patients with panic disorder vs. non-clinical controls. The study describes estimated cutoff points for the sample. Suggested cutoff points for CTQ scales according to Youden's index were identical to the American cutoff points for physical and emotional abuse and for physical neglect. For emotional neglect, the authors used a cutoff one point higher, and for sexual abuse, two points higher. ${ }^{27}$ We decided to keep the American scores for the following reasons: a) the Brazilian study was not designed to validate the scale, and the sample lacked appropriate size and representativeness in order to determine national standards for cutoff points; b) CTQ scores may range from 0 to 25 points for each type of trauma score, so the effect of 1-2 point difference in only two of the subscales is minimal, with no impact on the results (also, this difference was used in only one study, i.e., has not been tested more broadly); and c) the Brazilian study does not estimate cutoff points for the various degrees of trauma severity, as in the original American cutoff recommendation. Nevertheless, we also analyzed the association between trauma scores and loss of functionality using the continuous trauma scale: results were consistent with the categorized analysis.

3) The retrospective design of our study, with the use of self-report data about childhood trauma, may have introduced recall bias and consequently overestimation of trauma prevalence. However, a recent meta-analysis of studies using external corroboration of self-reports revealed that false-negative reports are more frequent than false-positive ones, leading to downward biases in estimated associations between early adversity and outcome variables. In order to increase the validity of self-reports, validated psychometric instruments should be used. ${ }^{36}$ Our sample showed a very high prevalence of self-report trauma (96.5\%); even if false-negative reports were present, the prevalence of such bias was, at maximum, $3.5 \%$.

Despite all limitations, this study provides further evidence that history of childhood trauma is associated with loss of functionality in FM, and should therefore be evaluated as an important predictive factor of functional loss in adult women with FM. These results could be important in the treatment of individuals who suffer from this complex syndrome.

Further research in this area will allow for a better understanding of FM heterogeneity and different response patterns. In addition, the hypothesis that traumatized children may manifest different syndromes throughout their development, with diverse consequences, should be further studied. New studies are also required to elucidate the pathophysiology, as well as the development of strategies for preventing and treating FM. The impact of childhood trauma and the role of depression on the clinical course of FM and response to treatment should be further evaluated. The systematic study of the natural history of FM, including psychological and neuroendocrine mechanisms of action, as well as of the psychosomatic pathways through which early childhood trauma results in extensive damages throughout life, could facilitate the search for effective interventions. In sum, findings in the childhood trauma area should be highlighted because of their significance in detection and prevention practices, and also to stimulate further study from various perspectives, with a special focus on finding effective treatments for this complex syndrome. 


\section{References}

1. Wolfe F, Smythe HA, Yunus MB, Bennett RM, Bombardier C, Goldenberg DL, et al. The American College of Rheumatology 1990 criteria for the classification of fibromyalgia. Report of the Multicenter Criteria Committee. Arthritis Rheum. 1990;33:160-72.

2. Verbunt JA, Pernot DH, Smeets RJ. Disability and quality of life in patients with fibromyalgia. Health Qual Life Outcomes. 2008;22:1-8.

3. Ofluoglu D, Berker N, Güven Z, Canbulat N, Yilmaz IT, Kayhan O. Quality of life in patients with fibromyalgia syndrome and rheumatoid arthritis. Clin Rheumatol. 2005;24:490-2.

4. Bennett RM. Fibromyalgia: present to future. Curr Pain Headache Rep. 2004;8:379-84.

5. Weissbecker I, Floyd A, Dedert E, Salmon P, Sephton S. Childhood trauma and diurnal cortisol disruption in fibromyalgia syndrome. Psychoneuroendocrinology. 2006;31:312-24.

6. Boisset-Pioro MH, Esdaile JM, Fitzcharles MA. Sexual and physical abuse in women with fibromyalgia syndrome. Arthritis Rheum. 1995; 38:235-41.

7. Imbierowicz K, Egle UT. Childhood adversities in patients with fibromyalgia and somatoform pain disorder. Eur J Pain. 2003;7:113-9.

8. Walker EA, Keegan D, Gardner G, Sullivan M, Katon WJ, Bernstein D. Psychosocial factors in fibromyalgia compared with rheumatoid arthritis: II sexual, physical, and emotional abuse and neglect. Psychosom Med. 1997;59:572-7.

9. McEwen BS. Protective and damaging effects of stress mediators: allostasis and allostatic load. N Engl J Med. 1998;338:171-9.

10. Low LA, Schweinhardt P. Early life adversity as a risk factor for fibromyalgia in later life. Pain Res Treat. 2012;2012:140832. doi: $10.1155 / 2012 / 140832$.

11. Winfield JB. Does pain in fibromyalgia reflect somatization? Arthritis Rheum. 2001;44:751-3.

12. Fietta $P$, Fietta $P$, Manganelli $P$. Fibromyalgia and psychiatric disor ders. Acta Biomed. 2007;78:88-95.

13. Thieme K, Turk DC, Flor H. Comorbid depression and anxiety in fibromyalgia syndrome: relationship to somatic and psychosocial variables. Psychosom Med. 2004;66:837-44.

14. Taylor ML, Trotter DR, Csuka ME. The prevalence of sexual abuse in women with fibromyalgia. Arthritis Rheum. 1995;38:229-34.

15. Alexander RW, Bradley LA, Alarcón GS, Triana-Alexander M, Aaron LA, Alberts KR, et al. Sexual and physical abuse in women with fibromyalgia: association with outpatient health care utilization and pain medication usage. Arthritis Care Res. 1998;11:102-15.

16. Ciccone DS, Elliott DK, Chandler HK, Nayak S, Raphael KG. Sexual and physical abuse in women with fibromyalgia syndrome: a test of the trauma hypothesis. Clin J Pain. 2005;21:378-86.

17. Walen HR, Cronan PA, Bigatti SM. Factors associated with healthcare costs in women with fibromialgia. Am J Manag Care. 2001;25:39-47.

18. McBeth J, Macfarlane GJ, Benjamin S, Morris S, Silman AJ. The association between tender points, psychological distress, and adverse childhood experiences: a communitybased study. Arthritis Rheum. 1999;42:1397-404.

19. Bernstein DP, Stein JA, Newcomb MD, Walker E, Pogge D, Ahluvalia $\mathrm{T}$, et al. Development and validation of a brief screening version of the Childhood Trauma Questionnaire. Child Abuse Negl. 2003;27:169-90.
20. Bernstein DP, Fink L. Childhood Trauma Questionnaire: a retrospective self-report: manual. San Antonio: The Psychological Corporation; 1998.

21. Bernstein DP, Fink L, Handelsman L, Foote J, Lovejoy $M$, Wenzel $K$, et al. Initial reliability and validity of a new retrospective measure of child abuse and neglect. Am J Psychiatry. 1994;151:1132-6.

22. Grassi-Oliveira R, Pezzi JC, Stein LM. Translation and content validation of the Childhood Trauma Questionnaire into Portuguese language. Rev Saude Publica. 2006;40:249-55.

23. Burckhardt CS, Clark SR, Bennett RM. The fibromyalgia impact questionnaire: development and validation. J Rheumatol. 1991;18:728-33.

24. Marques AP, Santos AM, Assumpção A, Matsutani LA, Lage LV, Pereira CA. Validação da versão brasileira do Fibromyalgia Impact Questionnaire (FIQ). Rev Bras Reumatol. 2006;46:24-31.

25. Cacace E, Ruggiero V, Anedda C, Denotti A, Minerba L, Perpignano G. Quality of life and associated clinical distress in fibromyalgia. Reumatismo. 2006;58:226-9.

26. Amorim P. Mini International Neuropsychiatric Interview (MINI): validação de entrevista breve para diagnóstico de transtornos mentais. Rev Bras Psiquiatr. 2000;22:106-15.

27. Seganfredo AC, Torres M, Salum GA, Blaya C, Acosta A, Eizirik $\mathrm{CL}$, et al. Gender differences in the associations between childhood trauma and parental bonding in panic disorder. Rev Bras Psiquiatr. 2009;31:314-21.

28. Chapman DP, Whitfield CL, Felitti VJ, Dube SR, Edwards VJ, Anda RF. Adverse childhood experiences and the risk of depressive disorders in adulthood. J Affect Disord. 2004; 82:217-25.

29. Heim C, Wagner D, Maloney E, Papanicolaou DA, Solomon L, Jones JF, et al. Early adverse experience and risk for chronic fatigue syndrome: results from a population-based study. Arch Gen Psychiatry. 2006;63:1258-66.

30. Felitti VJ, Anda RF, Nordenberg D, Williamson DF, Spitz $A M$, Edwards $V$, et al. Relationship of childhood abuse and household dysfunction to many of the leading causes of death in adults: the Adverse Childhood Experiences (ACE) Study. Am J Prev Med. 1998;14:245-58.

31. Widom CS. Posttraumatic stress disorder in abused and neglected children grown up. Am J Psychiatry. 1999;156:1223-9.

32. Agid O, Shapira B, Zislin J, Ritsner M, Hanin B, Murad H, et al. Environment and vulnerability to major psychiatric illness: a case control study of early parental loss in major depression, bipolar disorder and schizophrenia. Mol Psychiatry. 1999;4:163-72.

33. Müller W, Schneider EM, Stratz T. The classification of fibromyalgia syndrome. Rheumatol Int. 2007;27:1005-10.

34. Aisenstein $M$. The indissociable unity of psyche and soma: a view from the Paris Psychosomatic School. Int J Psychoanal. 2006;87:667-80.

35. Finestone HM, Stenn P, Davies F, Stalker C, Fry R, Koumanis J. Chronic pain and health care utilization in women with a history of childhood sexual abuse. Child Abuse Negl. 2000;24:547-56.

36. Hardt J, Rutter M. Validity of adult retrospective reports of adverse childhood experiences: review of the evidence. J Child Psychol Psychiatry. 2004;45:260-73.

\section{Correspondence}

Ana Paula Mezacaza Filippon

Rua Cartro Alves, 915/202, Independência

90430-131 - Porto Alegre, RS - Brazil

Tel. : +55 (51) 3013.4490

E-mail: anafilippon@yahoo.com.br 